\title{
Tense, Aspect, and Argument Structure
}

\author{
Toshiyuki Ogihara \\ University of Washington
}

\section{Preliminaries}

This paper is concerned with an intriguing difference between Japanese and English involving the progressive form be $V$-ing and the -te iru form as well as the passive constructions in the two languages. Some of the complex semantic properties of the -te iru construction in Japanese are discussed in Ogihara (1998), where I present a proposal to account for the multiple interpretations associated with this construction. This paper is a follow-up to this paper and attempts to present an improved proposal. In order to help the reader to understand my position, I shall start with a short description of the various interpretations associated with -te iru by comparing its behavior with that of the be $V$-ing form in English.

Vendler (1957) establishes four aspectual classes of verbs and characterizes them as in (1).
a. John was in Seattle. [state]
b. John drove his car. [activity]
c. John built a house. [accomplishment]
d. John fell asleep. [achievement]

One important diagnostic test for the classification proposed here is the progressive. (1a) clearly does not progressivize, whereas (1b) and (1c) clearly do. Vendler thought that achievements, which are intuitively descriptions of near-instantaneous events, do not progressivize. It tumed out that they also progressivize on a par with verbs in the other two non-stative verb classes. As shown in (2), verbs that belong to three of the four verb categories can be used in the progressive form.
a. *John was being in Seattle. [state]
b. John was driving his car. [activity]
c. John was building a house. [accomplishment]
d. John was falling asleep. [achievement]

In (2d), the progressive form is used to describe a stage before the event in question obtains. Compare this with the aspectual classification of Japanese verbs given in (3), which is essentially the same as that of Kindaichi (1950). ${ }^{1}$ 
(3)
a. Taroo-wa Tokyo-ni i-ta. [state]
Taro-TOP Tokyo-DAT be-PAST
'Taro was in Tokyo.'
b. Taroo-wa kuruma-o untensi-ta. [activity]
Taro-TOP car-ACC drive-PAST
'Taro drove [the] car.'
c. Taroo-wa ie-o tate-ta. [accomplishment]
Taro-TOP house-ACC build-PAST
'Taro built a house.'
d. Taroo-wa nemuri-ni tui-ta. [achievement]
Taro-ACC sleep-DAT begin/arrive-PAST
'Taro fell asleep.'

It turns out that all verbs other than stative verbs can occur in the -te iru form as shown in (4).
a. *Taroo-wa Tokyo-ni i-te i-ta. [state]
Taro-TOP Tokyo-DAT be-TE IRU-PAST Intended: 'Taro was in Tokyo.'
b. Taroo-wa kuruma-o untensi-te i-ta. [activity]
Taro-TOP car-ACC drive-TE IRU-PAST
'Taro was driving [the] car.'
c. Taroo-wa ie-o tate-te i-ta. [accomplishment]
Taro-TOP house-ACC build-TE IRU-PAST
'Taro was building a house.'
d. Taroo-wa nemuri-ni tui-te i-ta. [achievement]
Taro-ACC sleep-DAT begin/arrive-TE IRU-PAST
'Taro was asleep (as a result of having fallen asleep).'

However, when we compare (2d) and (4d), we notice that they receive distinct interpretations. (2d) describes a situation that obtains before John actually falls asleep, whereas (4d) describes a situation after Taro falls asleep, which can be characterized in terms of the adjective asleep as indicated in the English gloss. Put in slightly more formal terms, (2d) entails that Taro was not (yet) asleep, whereas (4d) entails that the Taro was (already) asleep. This contrast between the English progressive and the -te iru form in Japanese is striking. One cannot describe this simply by saying that when the verb in the sentence in question is an achievement verb, there is a semantic difference between the English progressive and the -te iru form in Japanese. We will discuss two relevant facts here.

First, Kindaichi (1950) points out that Japanese has many transitiveintransitive verb pairs such that the members of each pair involve the same stem and have contrasting aspectual properties in the -te iru form. Let us consider the case of simeru 'close' (transitive) and simaru 'close' (intransitive) as an illustrative example. They both describe "closing events" and do not seem to exhibit drastic semantic differences when they occur in the simple past as in (5a-b), except that (5a) overtly refers to an agentive entity whereas (5b) does not. 

a. Taroo-wa doa-o sime-ta.
Taro-TOP door-ACC close PAST
'Taro closed the door.'
b. Doa-ga simat-ta.
door-NOM close-PAST
'The door closed.'

Both (5a) and (5b) entail that there was a past time at which the door in question was closed. When the verb occurs in the -te iru form, however, these two verbs are used to describe totally different situations. (6a) involves a transitive verb simeru 'close' and can only receive a progressive interpretation, whereas (6b) involves an intransitive verb simaru 'close' and can only receive a resultative (or adjectival) interpretation.
a. Taroo-wa ima doa-o sime-te iru.
Taro-TOP now door-ACC close (tv.)-TE IRU-PRES
'Taro is closing the door now.' [progressive]
b. Doa-wa ima simat-te iru.
door-TOP now close (iv.)-TE IRU-PRES
'The door is closed now.' [resultative/adjectival]

If we follow Kindaichi's verb classification system faithfully, we are obliged to conclude that simeru 'close' (transitive) is a durative verb, whereas simaru 'close' (intransitive) is an instantaneous verb. However, as we shall see below, this way of encoding the difference in question is not the best way to deal with it since similar verb pairs in English (such as close (transitive) and close (intransitive)) do not exhibit this contrast at all. Moreover, this contrast should not be attributed to the fact that (6a) involves a transitive verb whereas (6b) involves an intransitive verb. Some intransitive verbs such as hasiru 'run' receive as their default interpretations on-going process interpretations as the example (7) suggests.

(7) Taroo-wa ima hasit-te iru.

Taro-TOP now run-TE IRU-PRES

'Taro is now running.'

Second, a passive sentence in the -te iru form often induces a resultative interpretation. Note the contrast between (8a) and (8b). Note also that a nonprogressive passive sentence such as (8c) must receive an eventive interpretation and cannot receive an adjectival interpretation.
a. Hitobito-ga dooro-o hosoosi-te iru. people-NOM road-ACC pave-TE IRU-PRES 'The people are paving a/the road.' [progressive]
b. Kono dooro-wa hosoos-are-te iru. this road-TOP pave-PASSIVE-TE IRU-PRES 'This road is paved.' [resultative]
c. Kono dooro-wa hosoos-are-ru. this road-TOP pave-PASSIVE-PRES 'This road will be paved.' [eventive] 
(8a) receives an on-going process reading, whereas $(8 b)$ receives a resultant state reading. As in (6), the fact that the subject of (8a) is an AGENT whereas the subject of (8b) is a THEME makes a difference here. In (8a-b), the road undergoes a clear change characterized by the lexical meaning of the verb hosoo-suru 'pave.' On the other hand, the people do not obtain any stage-level property (Carlson 1977) that is characterized by the lexical meaning of this verb. ${ }^{2}$ The fact that $(8 \mathrm{c})$ only receives an eventive interpretation will be of interest when we turn to English passive sentences.

The descriptive generalization is that when the subject NP of a sentence in the -te iru form has an agentive thematic role, this sentence can receive an on-going process interpretation, whereas a sentence with the subject NP that has a theme thematic role must receive a resultative interpretation. It is Okuda $(1977,1984)$ who first suggested that we should look at the semantic roles that various subject NPs play in order to account for the aspectual properties of Japanese sentences. For example, (6a) describes an action that the referent of the subject NP engages in, whereas (6b) describes a change that the referent of the subject NP undergoes. In other words, the contrast is due to the different (thematic) roles that the subject NPs assume in (6a-b). In (6a) the subject is an AGENT, whereas in (6b) the subject is a THEME. Such terms as AGENT and THEME are often invoked in the syntactic literature, but their properties are rarely characterized in formal terms. Roughly speaking, THEME is an object that undergoes some change and/or obtains some state that is inherent in the meaning of the predicate in question. For example, the door is a THEME in (6a--b) in that it must move from an opened position to a closed position (thereby obtaining the property of being closed after the event). On the other hand, the truth of (5a) does not guarantee that Taro obtains a particular stagelevel property.

English differs from Japanese on two counts. First, the English progressive form (be $V$-ing) does not induce result state interpretations regardless of the thematic role associated with the subject NP. For example, just as in Japanese, English has transitive-intransitive verb pairs that are morphologically and semantically related. In some cases, these verbs are identical in form as in the case of close. Consider $(9 \mathrm{a}-\mathrm{b})$.

a. John is closing the door (now).

b. The door is closing (now).

Both (9a) and (9b) receive on-going process interpretations. Thus, it appears that the semantics of the English progressive is insensitive to differences in argument structure. Moreover, the fact that $(9 \mathrm{~b})$ is acceptable seems to show that The door closes is an accomplishment. Thus, if we decided that the aspectual classification of verbs determines their behavior with respect to the progressive (or the -te iru form), then we would have to conclude that the intransitive verb close in English and the intransitive verb simaru 'close' in Japanese belong to different aspectual classes.

Second, English passivization is capable of producing resultative interpretations, whereas Japanese passivization cannot. $(10 \mathrm{a}-\mathrm{b})$ describe a resultant state produced by an event associated with the active form of the predicate in question. On the other hand, (10c-d) describe events that took place in 1997, not their resultant states. 
a. John is (now) retired.

b. This paper is (now) published.

c. John retired in 1997.

d. The MIT Press published John's paper in 1997.

In (10a), what the sentence describes is the state of John being retired; in (10b), it is the fact that the paper is now in print. (8b) and $(10 a-b)$ are similar in that they all involve a subject that undergoes some change. What is interesting about the Japanese example (8b) and the English examples $(10 \mathrm{a}-\mathrm{b})$ is that the former involves the -te iru form whereas the latter do not involve any aspectual morpheme. On the other hand, some passive sentences in English (e.g., (11)) do occur in the be $V$-ing form and produce on-going process interpretations, unlike Japanese passive sentences in the -te iru form.

The building is being destroyed.

The above contrast between English and Japanese is complex and requires a careful examination of the relevant data. To account for the above data, I shall propose a framework in which any eventuality argument of a thematic role can be a proper part of an eventuality that serves as an argument of the verbal predicate.

\section{A Previous Proposal and Its Problems}

In my earlier work (Ogihara 1998), I proposed to distinguish between transitive verbs and their intransitive counterparts as involving different eventuality types, thereby predicting their semantic differences in the -te ir $u$ form. In particular, I posited a new analysis of so-called instantaneous verbs (roughly equivalent to achievements in English). This proposal can be summarized as follows: I first propose that the semantic contribution made by the morpheme -te iru should be described as in (12). (This is a simplified version in that it abstracts away from the imperfective paradox (Dowty 1979)).

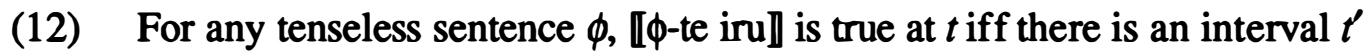
that completely contains $t$ (and $t$ is neither an initial subinterval nor a final subinterval of $t^{\prime}$ ) such that $\llbracket \phi \rrbracket$ is true at $t^{\prime}$.

The idea is that -te iru is analogous to the English progressive in that it is used to claim that the time of evaluation is part of another interval at which the sentence without the morpheme -te iru is true. Then I propose that the transitive verb simeru 'close' and its intransitive counterpart simaru 'close' (and many similar pairs) involve different eventuality types. According to Kindaichi (1950), the former involves a durative event, whereas the latter involves an instantaneous event. As far as transitive verbs are concerned, I adopted Kindaichi's proposal in that the event involved in (6a) is the process of Taro's closing the door. On the other hand, I slightly modified Kindaichi's proposal regarding verbs like simaru 'close' (intransitive). According to the revised analysis of so-called "instantaneous verbs," an eventuality that verifies (6b) can be an instantaneous event but can also be an extended event. The idea can be explained informally as follows: when the door 
closes, an eventuality that only contains the initial point at which the door is completely closed counts as one that verifies the sentence Doa-ga simaru 'the door closes,' but the proposal leaves open the possibility that more extended events that share the same initial state, namely the one that only contains the initial point at which the door is completely closed, can also verify the same sentence. On the basis of this distinction between the transitive verb simeru 'close' and the intransitive verb simaru 'close', we can account for the semantic difference between (6a) and (6b). Schematically, the difference between (6a) and (6b) is described as in (13a-b).

a.

(6a) is toye here.

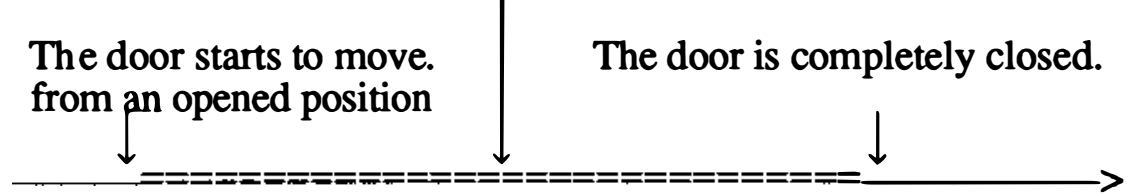

b.

(6b) is trye here.

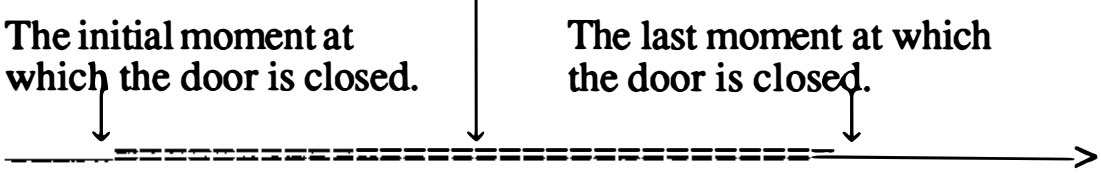

This proposal is descriptively adequate as far as the behavior of -te iru is concerned. However, this proposal is inadequate on many counts as I pointed out in Ogihara (to appear). Since one and the same "situation" can be described by two sentences that involve morphologically related verbs such as simeru 'close' and simaru 'close,' it is questionable whether they do in fact involve two different types of eventuality. Consider (14a-b).
a. Taroo-ga doa-o sime-ta.
Taro-NOM door-ACC close-PAST
'Taro closed the door.'
b. Doa-ga simat-ta.
door-NOM close-PAST
'The door closed.'

It is quite possible to assume that $(14 a-b)$ are used to depict the same situation. For example, if Taro closes the door and Jiro sees him do so, then Jiro presumably uses (14a) to describe what happened. On the other hand, if Taro closes the door in such a way that he is not visible from Hanako, then Hanako could describe what happened with (14b). In this particular case, (14a) and (14b) appear to describe the "same event." However, my earlier proposal is forced to say that they concern different events. If this is the only problem with my previous proposal, I could contend that (14a) concerns an event that contains the process part as well as the initial point of the state, whereas (14b) only contains the initial point of the state; the attainment of a relevant result state (i.e., the state of the door's being closed) is entailed in both cases, which arguably gives us the impression that (14a) and (14b) involve the same eventuality. However, this argument does not seem to hold 
because in examples like (15a-b) the same adverbial can be used in both types of sentences, indicating that they indeed describe the same (type of) event.
a. Taroo-ga sanzyuu-byoo-de doa-o sime-ta.
Taro-NOM 30-sec.-in door-ACC close-PAST
'Taro closed the door in 30 seconds.'
b. sanzyuu-byoo-de doa-ga simat-ta. 30-sec.-in door-NOM close-PAST
'The door closed in 30 seconds.'

The fact that the same adverbial 30-byoo-de 'in 30 seconds' is used in (15a) and (15b) indicates that both verbal predicates must contain relevant information about the process part. Japanese de-adverbials such as 30-byoo-de 'in 30 seconds' are slightly different from in-adverbials in English in that they must refer to the length of some process associated with an event and cannot be used to measure the temporal distance between some contextually salient time and the (relatively short) time at which some event or state takes place. For example, (16a) is perfectly acceptable although be here is a plain stative predicate that does not have a process associated with it. By contrast, (16b) is unacceptable.

a. John will be here in five minutes.

b. *Taroo-wa go-fun-de koko-ni iru. Taro-TOP five-minute-in here-at be-PRES Intended: 'Taro will be here in five minutes.'

In addition to this language-particular problem in Japanese, my earlier approach faces a cross-linguistic problem because this leads us to assume that the intransitive verb simaru 'close' in Japanese and the intransitive verb close in English have very different semantic properties, which is counterintuitive. As mentioned above, Okuda's observation is worth noting in this connection. His point is that the events described by (15a) and (15b) do not differ from each other with respect to temporal duration; the main difference is that (15a) describes the action of the entity denoted by the subject, whereas ( $15 \mathrm{~b}$ ) describes the change that the entity denoted by the subject undergoes. The question is how we encode this intuitive idea formally. The proposal I posit is an attempt to execute Okuda's idea in a formalized system, and it accounts for the above data.

\section{Toward a Solution}

In the tradition of formal semantics, two types of event-based systems have been proposed: (i) the main predicate of a sentence takes as its arguments a "normal" individual and an event; (ii) the verbal predicate is a predicate of events, and event participants are introduced in terms of thematic roles that denote relations between events and individuals (Parsons 1990, Krifka 1992). In these systems, the temporal reference of events is described in terms of a temporal trace function $\tau$ (Link 1987) which maps an event to its "run time." For example, (17a) is rendered as in (17b) by (i), while it is analyzed as in (17c) by (ii). 

a. John cried.
b. $\exists e[\tau(e)<$ now $\wedge \operatorname{cry}(j, e)]$
c. $\exists e[\tau(e)<$ now $\wedge \operatorname{cry}(e) \wedge \operatorname{AGENT}(e, j)]$

A sentence that involves a transitive verb such as (18a) is analyzed as in (18b) or as in (18c).
a. John hit Bill.
b. $\exists e[\tau(e)<$ now $\wedge \operatorname{hit}(j, b, e)]$
c. $\exists e[\tau(e)<$ now $\wedge \operatorname{hit}(e) \wedge \operatorname{AGENT}(e, j) \wedge \operatorname{PATIENT}(e, b)]$

At first, we do not find any significant difference between the two systems. In particular, they both have difficulty explaining the fact that in Japanese the thematic role associated with the subject NP affects the aspectual property of the entire sentence. However, the system proposed by Parsons and Krifka is more flexible in that the verbal predicate (e.g., hit) and thematic roles (e.g., AGENT) translate as separate predicates requiring an event argument. This allows us to modify the system in such a way that the verbal predicate and a relevant thematic role do not have to share the same event argument.

According to Krifka's (1992) proposal, there is a set of events such that the postulate in (19) (a variant of (P.2) on p. 32) holds of it.

$$
\forall e_{1}, e_{2} \exists e_{3}\left[e_{1}\left\lfloor e_{2}=e_{3}\right]\right.
$$

The symbol "I!" is used to indicate the join operation, which is like gluing two objects together. Put informally, (19) says that given any events $e_{1}$ and $e_{2}$, their sum is also an event. The basic pre-theoretical intuition about the concept of event is that it is a dynamic occurrence of something, whereas a state is understood to be a continuation of some stable situation. Let us assume that the set of events in Krifka's proposal is a set of eventualities in the sense of Bach (1986), which contains both events and states. Then it follows that the set of eventualities contains heterogeneous eventualities that are made up of event parts and state parts. The proposal I defend employs this type of eventuality in a crucial way. For example, an eventuality associated with Taro's closing the door involves both an event part which intuitively corresponds to the process of Taro's closing the door and a state part which corresponds to the state of the door's being (completely) closed. Likewise, an eventuality associated with the door's closing also contains the process of the door's closing and the state of the door's being closed. On this assumption, (14a) and (14b) can be verified by the same event. The idea of using an enriched eventuality in both cases may soem questionable at first because it looks as though this proposal does not receive much empirical support. However, it turns out that the result state part of the eventuality is needed even in sentences containing a transitive verb such as (20).

(20) Taroo-wa mise-o mikka-kan sime-ta.

Taro-TOP shop-ACC three-days-long close-PAST

'Taro closed [his] shop for three days.' 
The adverbial mikka-kan 'for three days' refers to the length of the state of the shop's being closed, not the length of the action required to close Taro's shop. Thus, we should assume that the meaning of the transitive verb simeru 'close' contains information about the result state part as well as the process part.

Let us now look at the details of the system I propose. In this system, two contrastive verbal predicates such as simeru 'close' (transitive) and simaru 'close' (intransitive) are allowed to interact with the same eventuality and yet produce different interpretations when they occur in the -te iru form. The basic ideas that I explore in this paper are (i) that the eventuality associated with a thematic role does not have to be the same as that associated with the verbal predicate and (ii) that tense only interacts with the eventuality argument of the thematic role associated with the subject NP. To be more specific, I shall deal with the above data by adopting the idea that given an eventuality described by a verbal predicate, its participants may be related to proper parts of this eventuality. For example, (5a) is analyzed as in (21).

$$
\exists e \exists s[\tau(e)<\text { now } \wedge \text { AGENT(Taro) }(e) \wedge \operatorname{close}(e \bigoplus s) \wedge \operatorname{THEME}(\text { the-door })(s)]
$$

The symbol $\oplus$ is used as a binary connective that puts two eventualities together to yield a new plural eventuality (Link 1983). For example, the expression $e \oplus s$ in (21) indicates a hybrid eventuality that consists of an event part and a state part. Technically, we can regard events and states as different sorts that belong to the set of eventualities. Assuming that we have a type associated with eventualities (say, type $e v), \oplus$ is an expression of type $\langle e v,\langle e v, e v\rangle\rangle$. Then, we can say that both $e$ and $s$ in (21) are variables of the type $e v$ but range over events and states, respectively, which are disjoint subsets of the set of eventualities. Given that $\oplus$ can be used to produce hybrid eventualities, I assume that the set of eventualities consists of three types of entities: events, states, and hybrid eventualities. An important technical characteristic of this approach is that the eventuality that interacts with tense (i.e., $e$ ) is merely part of the eventuality that serves as the argument of the verbal predicate close (i.e., $e \oplus s$ ). Note also that the state $s$ that serves as the eventuality argument of THEME does not interact with tense. I will explain in detail how this proposal accounts for the above Japanese data.

In the proposal I defend, thematic role differences can be understood to involve different ways in which individuals interact with eventualities. For example, both simeru 'close' (transitive verb) and simaru 'close' (intransitive verb) can involve the same event, but their subject NPs interact with it in different ways. Let us discuss $(14 a-b)$ again, which are repeated here as $(22 a-b)$.

a. Taroo-ga doa-o sime-ta.

Taro-NOM door-ACC close-PAST

'Taro closed the door.'

b. Doa-ga simat-ta.

door-NOM close-PAST

'The door closed.'

My proposal concerning Japanese sentences involving verb pairs such as simeru 'close' (transitive) and simaru 'close' (intransitive) is that the agentive NP bears the theta role AGENT and the non-agentive NP the theta role RESULT, which 
replaces the more familiar term THEME. The assignment of theta roles by the two verbs in question is specified as in (23).
a. simeru 'close' (transitive verb): assigns the thematic role AGENT to the subject NP; assigns the thematic role RESULT to the object NP
b. simaru 'close' (intransitive): assigns the thematic role RESULT to the subject NP

Note here that some intransitive verbs such as hasiru 'run' are required to assign the thematic role AGENT to the subject NP because (24) receives an on-going process interpretation.

(24) Taroo-wa ima hasit-te inu.

Taro-TOP now run-TE IRU-PRES

'Taro is now running.'

What I have just described can be accounted for more succinctly by adopting the Unaccusative Hypothesis proposed by Perlmutter (1978). According to the Unaccusative Hypothesis, intransitive verbs come in two types: unergatives and unaccusatives. These two types are distinguished in the GB literature (Burzio 1986) in terms of syntactic configuration: an unergative verb takes a D-structure subject and no object, whereas an unaccusative verb takes a D-structure object and no subject. According to this hypothesis, simaru 'close' (intransitive) is an unaccusative verb, whereas hasiru 'run' is an unergative verb. Takezawa (1991) and Tsujimura (1991) entertain this hypothesis. Given the assumption that there is a correlation between thematic roles assigned to NPs and their D-structure positions, we can posit $(25 \mathrm{a}-\mathrm{b})$.

(25) a. The thematic role AGENT can only be assigned to the D-structure subject position

b. The thematic role RESULT can only be assigned to the D-structure object position

Turning to the translation of verbal predicates, we can use the same verbal predicate close in the translations of sentences involving simeru 'close' (transitive) and simaru 'close' (intransitive). close is a predicate of eventualities and requires as its argument a hybrid eventuality that consists of an "event part" and a "state part." I assume that predicates of eventualities that are associated with eventive verbs in Japanese (durative and instantaneous verbs in Kindaichi's terms) are subject to the constraints stated in (26).

(26) For any predicate of eventualities $\phi$ and eventuality terms $e$ and $s$, if $\llbracket \phi(e \oplus s) \rrbracket=1$, then the following hold:

(i) $\llbracket \tau(e) \rrbracket \cup \llbracket \tau(s) \rrbracket$ is an interval, and the final moment of $\llbracket \tau(e) \rrbracket$ coincides with the initial moment of $\llbracket \tau(s) \rrbracket$.

(ii) For any eventuality terms $e_{1}$ and $s_{1}$ such that $\llbracket e \oplus s \rrbracket$ and $\llbracket e_{1} \oplus s_{1} \rrbracket$ overlap and $\llbracket \phi\left(e_{1} \oplus s_{1}\right) \rrbracket=1, \llbracket \tau(e) \rrbracket \cap \llbracket \tau(s) \rrbracket=\llbracket \tau\left(e_{1}\right) \rrbracket \cap \llbracket \tau\left(s_{1}\right) \rrbracket$. 
The constraints given in (26) guarantee the following: (i) any "eventive verb" actually involves a resultant state as part of its lexical meaning, and this state obtains as soon as the event is complete; (ii) any overlapping eventualities characterized by the same verbal predicate must share the same moment at which the crucial change of state takes place.

Assuming some compositional semantic rules, I analyze (22a-b) as in (27ab), respectively. As promised above, the same eventuality predicate close is used to translate the transitive verb simeru 'close' and the intransitive verb simaru 'close.'

$$
\begin{aligned}
& \text { a. } \exists e \exists s[\tau(e)<\text { now } \wedge \text { AGENT(Taro })(e) \wedge \operatorname{close}(e \oplus s) \wedge \operatorname{RESULT}(\text { the- } \\
& \text { door })(s)] \\
& \text { b. } \exists e \exists s[\tau(s)<\text { now } \wedge \operatorname{RESULT}(\text { the-door })(s) \wedge \operatorname{close}(e \oplus s)]
\end{aligned}
$$

The constraints stated in (26) guarantee that $(27 a-b)$ give us the right results. (27a) says that the closing event took place in the past because the event of which Taro is the agent is in the past and this event is immediately followed by an initial state of the door's being closed. On the other hand, (27b) requires that an initial portion of the result state (i.e. the door's being closed) be located in the past without entailing that the door is no longer closed. It is important to note that both (27a) and (27b) guarantee that at some past time the door obtained the property of being closed. This is the desired result.

We now turn to the semantics of -te iru. I propose (28) to characterize the semantic contribution of the morpheme -te iru (again abstracting away from the cases that involve the imperfective paradox). ${ }^{3}$

(28) For any predicate $\phi$, individual $a$, eventuality $e$, and interval $t$, $\llbracket \phi$-te iru $\rrbracket(a)(e)=1$ at $t$ iff there are eventualities $e$ and $e_{1}$ such that the temporal trace of $e$ equals $t$ and $e \subset e_{1}$ and $\llbracket \phi \rrbracket(a)\left(e_{1}\right)=1$.

(28) states that an eventuality with respect to which a sentence in the -te iru form is true must be part of an eventuality that makes the same sentence without the morpheme -te iru true. Since tense only interacts with the thematic role associated with the subject NP, $(22 a-b)$ and their progressive counterparts $(29 a-b)$ have different truth conditions. This enables us to explain the asymmetry noted above. To be more specific, I contend that the sentences (29a--b) have truth conditions described as in $(30 \mathrm{a}-\mathrm{b})$, respectively.

(29) a. Taroo-wa ima doa-o sime-te iru. Taro-TOP now door-ACC close (tv.)-TE IRU-PRES 'Taro is closing the door now.' [progressive]

b. Doa-wa ima simat-te inu. door-TOP now close (iv.)-TE IRU-PRES 'The door is closed now.' [resultative/adjectival] 
(30) a. (29a) is true at $t$ iff there are eventualities $e_{1}$ and $e_{2}$ such that the temporal trace of $e_{1}$ equals $t$ and $e_{1} \subset e_{2}$ and $\llbracket \lambda e \exists s[\operatorname{AGENT(Taro)}(e) \wedge$ $\operatorname{close}(e \oplus s) \wedge \operatorname{RESULT}($ the-door $)(s)] \rrbracket\left(e_{2}\right)=1$.

b. (29b) is true at $t$ iff there are eventualities $s_{1}$ and $s_{2}$ such that the temporal trace of $e_{1}$ equals $t$ and $e_{1} \subset s_{2}$ and $\llbracket \lambda s \exists e[R E S U L T($ thedoor $)(s) \wedge \operatorname{close}(e \oplus s)] \rrbracket\left(s_{2}\right)=1$.

(30a) indicates that (29a) has a progressive interpretation because its truth condition is that there is some current event that can be extended into an event such that Taro is its agent and it is a process part of a closing eventuality. This results in an ongoing process interpretation. On the other hand, (30b) shows that $(29 \mathrm{~b})$ receives a result state interpretation because a current state is part of a larger resultant state such that the door is its bearer and it is a result state part of a closing eventuality. This yields a result state reading.

This proposal also accounts for examples which involve passive sentences like $(8 \mathrm{a}-\mathrm{b})$ (repeated here as $(31 \mathrm{a}-\mathrm{b}))$.

a. Hitobito-ga dooro-o hosoosi-te iru. people-NOM road-ACC pave-TE IRU-PRES 'People are paving a/the road.' [progressive]

b. Kono dooro-wa hosoos-are-te iru. this road-TOP pave-PASSIVE-TE IRU-PRES 'This road is paved.' [resultative]

If we adopt the standard GB account according to which the S-structure subject of a passive sentence originates in the object position at D-structure, we need nothing new; $(25 \mathrm{a}-\mathrm{b})$ are the only rules we need to obtain the right result here. For example, in (32a) the role RESULT is assigned to the NP ano dooro 'that road' because it is a D-structure object. Thus, (32a) translates as in (32b).

a. Ano dooro-wa hosoos-are-ta.

That road-TOP pave-PASSIVE-PAST

'That road was paved.' [eventive]

b. $\exists e \exists s[\tau(s)<$ now $\wedge \operatorname{pave}(e \oplus s) \wedge \operatorname{RESULT}($ that-road $)(s)]$

(32b) says that there is a state in the past that the road has, and this state is an initial portion of a resulting state which is a part of a paving eventuality. (32a) only receives an eventive interpretation because it conveys information about an initial part of a relevant result state. In order to receive a progressive interpretation, it must be in the -te iru form. The proposal I defend predicts the truth conditions (33a-b) for $(31 a-b)$, respectively.

(33) a. (31a) is true at $t$ iff there are eventualities $e_{1}$ and $e_{2}$ such that the temporal extension of $e_{1}$ equals $t$ and $e_{1} \subset e_{2}$ and $\llbracket \lambda e \exists s\left[\operatorname{AGENT}(\right.$ people $)(e) \wedge \operatorname{pave}(e \oplus s) \wedge \operatorname{RESULT}($ the-road $)(s) \rrbracket\left(e_{2}\right)=$ 1.

b. (31b) is true at $t$ iff there are eventualities $s_{1}$ and $s_{2}$ such that the temporal extension of $s_{1}$ equals $t$ and $s_{1} \subset s_{2}$ and $\llbracket \lambda s \exists e[R E S U L T($ the$\operatorname{road})(s) \wedge \operatorname{pave}(e \oplus s) \rrbracket\left(s_{2}\right)=1$ 
It is clear from the above discussion that (33a) receives an on-going process interpretation, whereas $(33 \mathrm{~b})$ receives a result state interpretation. This is the desired result.

Let us now turn to English. One way of handling the difference between English and Japanese is to propose that object NPs receive different thematic roles in the two languages. I have contended that in Japanese a D-structure object NP receives the theta role RESULT. As for English, I argue that the object NP interacts with two relations simultaneously. These relations are used in my proposal to construct a complex thematic role. For our purposes, these relations are labeled as UNDERGOER and RESULT. For example, the difference between the transitive verb close and the intransitive verb close in English can be described as in (34).
a. close (transitive):
assigns the thematic role AGENT to the subject NP;
assigns the thematic role UNDERGOER-RESULT to the object NP
b. close (intransitive):
assigns the thematic role UNDERGOER-RESULT to the subject NP

By adopting the Unaccusative Hypothesis, we can claim that the intransitive verb close is an unaccusative verb. As a result, $(34 a-b)$ are subsumed under (35a-b).

(35) a. The thematic role AGENT is assigned to a D-structure subject NP.

b. The thematic role UNDERGOER-RESULT is assigned to a D-structure object.

$(36 a-b)$ are represented as in (37a-b), respectively.
a. John closed the door.
b. The door closed.
a. $\exists e \exists s[\tau(e)<$ now $\wedge \operatorname{close}(e \oplus s) \wedge \operatorname{AGENT}(\mathrm{John})(e) \wedge \mathrm{UNDERGOER}($ the- door $)(e) \wedge$ RESULT(the-door $)(s)]$
b. $\exists e \exists s[\tau(e)<$ now $\wedge$ close $(e \oplus s) \wedge$ UNDERGOER(the-door $)(e) \wedge$ RESULT(the-door)(s)]

As mentioned earlier, English does not exhibit any semantic difference between the transitive verb close and its intransitive counterpart. Thus, I am obliged to stipulate that in English, tense only interacts with events (and not with states). As a result, both (37a) and (37b) require that an event part of a closing eventuality obtain in the past. Then it is clear that when the progressive form is used in conjunction with (36a-b), the resulting sentences produce only on-going process interpretations. I assume the semantics of the progressive in English given in (38), which represents the standard view in the formal semantics literature. ${ }^{4}$

(38) For any predicate $\phi$, individual $a$, eventuality $e, \llbracket \mathrm{BE} \phi-\operatorname{ING} \rrbracket(a)(e)=1$ at an interval $t$ iff the temporal trace of $e$ is $t$ and there is an eventuality $e_{1}$ such that $e \supset e_{1}$ and $\llbracket \phi \rrbracket(a)(e)=1$ at $t$.

On the basis of this semantic analysis of the progressive, $(39 a-b)$ are analyzed as in $(40 \mathrm{a}-\mathrm{b})$. 
a. John is closing the door.

b. The door is closing.

(40) a. (39a) is true at $t$ iff there are eventualities $e_{1}$ and $e_{2}$ such that the

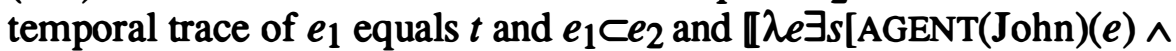

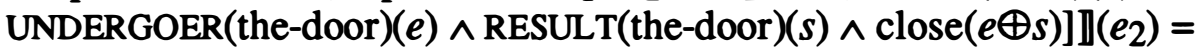
1.

b. (39b) is true at $t$ iff there are eventualities $e_{1}$ and $e_{2}$ such that the temporal trace of $e_{1}$ equals $t$ and $e_{1} \subset e_{2}$ and $\llbracket \lambda e \exists s$ [UNDERGOER(thedoor $)(e) \wedge \operatorname{RESULT}($ the-door $)(e) \wedge \operatorname{close}(e \oplus s)] \rrbracket\left(e_{2}\right)=1$.

(40a-b) receive on-going process interpretations as desired.

Regarding passivization, the proposal I defend can only account for eventive interpretations. Although this is not fully satisfactory, I believe that the treatment of adjectival passives is a complex matter that requires a separate paper. As for eventive passive interpretations, the above analysis predicts the right interpretations straightforwardly. Consider the examples in (41).

(41) a. The door was closed.

b. The door is being closed.

The eventive interpretation of (41a) is obtained by assuming that the door originates as a D-structure object and receives the theta role UNDERGOER-RESULT. Assuming as mentioned above that tense interacts only with events in English, we can analyze $(41 \mathrm{a}-\mathrm{b})$ as in $(42 \mathrm{a}-\mathrm{b})$, respectively.
a. $\exists e \exists s[\tau(e)<$ now $\wedge$ close $(e \oplus s) \wedge$ UNDERGOER(the-door $)(e) \wedge$ RESULT(the-door) (s)]
b. $\exists e_{2} \exists e \exists s\left[\tau\left(e_{2}\right)=\right.$ now $\wedge e_{2} \subset e \wedge \operatorname{close}(e \oplus s) \wedge$ UNDERGOER(the- door $)(e) \wedge \operatorname{RESULT}($ the-door $)(s)]$

(42a) requires that there exist in the past an event part of a closing eventuality of which the door is the undergoer. This amounts to an eventive interpretation. (42b) says that there is a current eventuality that is part of an event part of a closing eventuality. This means that it receives an on-going process interpretation.

\section{Final Remarks}

If I am correct, the proposal I defend in this paper shows that some cross-linguistic differences (aspectual differences, in particular) can be attributed to different thematic roles assigned to NPs, which in turn translate into distinct semantic interpretations. One important advantage of this approach is that it enables us to say that there are no fundamental differences between English and Japanese with respect to verbal predicates. By relegating the differences to argument structure, one can hope that the problems associated with aspect can be related to other syntactic and semantic issues. Another potential advantage of the approach defended here is that it is capable of explaining the behavior of in-adverbials and for-adverbials in English and their counterparts in Japanese. This is because the translation of each 
verbal predicate contains information about both the process part and the result state part of a relevant eventuality.

\section{Endnotes}

* I thank Irene Heim, Angelika Kratzer, Barry Schein for comments on earlier versions of this paper. All inadequacies are my own.

1 I differ from Kindaichi in that the distinction between activities and accomplishments is drawn here on a par with Vendler's classification of English verbs. Kindaichi's original proposal has the following four classes: stative verbs, durative verbs, and instantaneous verbs, and the "type 4" verbs.

2 There is an individual-level property that the agentive subject of (5a) obtains. It is the property of having opened the door (i.e., the denotation of $\lambda t \lambda x \exists t_{1} \exists y[y$ is a door \& $x$ opens $y$ at $\left.\left.t_{1} \& t_{1}<t\right]\right)$. However, there is no stage-level property the agent must obtain when (5a) is true. So it seems fair to say that the property in question is qualitatively different from that associated with the door (i.e., the property of being open).

3 I also ignore the complication involving so-called "experiential interpretations" associated with -te iru. See Ogihara (1998) for details.

${ }^{4}$ As was the case with the proposal for -te iru in Japanese given in (28), (38) is a simplified version in that it abstracts away from the imperfective paradox.

\section{References}

Bach, Emmon. (1986) "The Algebra of Events," Linguistics and Philosophy 9, 516.

Burzio, Luigi. (1986) Italian Syntax: A Government-Binding Approach, D. Reidel, Dordrecht.

Carlson, Gregory. (1977) Reference to Kinds in English, PhD dissertation, University of Massachusetts, Amherst.

Dowty, David. (1979) Word Meaning and Montague Grammar: The Semantics of Verbs and Times in Generative Semantics and in Montague's PTQ, D. Reidel, Dordrecht.

Kindaichi, Haruhiko (1950) "Kokugo dooshi no ichibunrui," [A Classification of Japanese Verbs] Kokugo Kenkyuu 15, 48-65.

Krifka, Manfred. (1992) "Thematic Relations as Links between Nominal Reference and Temporal Constitution," in Ivan A. Sag and Anna Szabolcsi (eds.), Lexical Matters, Center for the Study of Language and Information, distributed by Chicago University Press, pp. 29-53.

Link, Godehard. (1983) "The Logical Analysis of Plurals and Mass Terms: A Lattice-theoretical Approach," in Rainer Bäuerle, Christoph Schwarze, and Arnim von Stechow (eds.), Meaning, Use, and Interpretation of Language, W. de Gruyter, Berlin, pp. 302-323.

Link, Godehard. (1987) "Algebraic Semantics for Event Structures," in Jeroen Groenendijk, Martin Stokhof, and Frank Veltman (eds.), Proceedings of the 6th Amsterdam Colloquium, University of Amsterdam, Institute for Language, Logic, and Information, pp. 243-262. 
Ogihara, Toshiyuki. (1998) "The Ambiguity of the -te iru Form in Japanese," Journal of East Asian Linguistics 7, 87-120.

Ogihara, Toshiyuki. (to appear) "Chapter 11, Tense and Aspect," in Natsuko Tsujimura (ed.), The Handbook of Japanese Linguistics, Blackwell, Oxford.

Okuda, Yasuo. (1977) "Asupekuto no kenkyuu o megutte - Kindaichi teki dankai" [On the Study of Aspect - the Kindaichi stage]. Miyagi Kyooiku Daigaku Kokugo Kokubun 8. Also Reprinted in Okuda (1984).

Okuda, Yasuo. (1984) Kotoba no Kenkyuu Josetsu [An introduction to the study of language], Mugi Shoboo, Tokyo.

Parsons, Terence. (1990) Events in the Semantics of English: A Study in Subatomic Semantics, MIT Press, Cambridge.

Perlmutter, David. (1978) "Impersonal Passives and the Unaccusative Hypothesis," in J. Jaeger et al. (eds.), Proceedings of the Fourth Annual Meeting of the Berkeley Linguistics Society, University of California, Berkeley, pp. 157-189.

Takezawa, Kooichi (1991) "Judootai, nookakubun, bunri-fukanoo shoyuu koobun to -te iru no kaishaku," [Passive, Ergative case, Inalienable Possession, and the Interpretation of -te iru] in Yoshio Nitta (ed.), Nihongo no boisu to tadoosei, [The Voice and Transitivity in Japanese] Kurosio Shuppan, Tokyo.

Tsujimura, Natsuko. (1991) "On the Semantic Properties of Unaccusativity," Journal of Japanese Linguistics 11, 91-116.

Vendler, Zeno. (1957) "Verbs and Times," The Philosophical Review 66, 143160. 